\title{
Da verdade aos efeitos de verdade: contribuições das teorias semióticas e do discurso à comunicação em tempos de pós-verdade
}

\section{Tarcísio de Sá Cardoso}

Universidade Federal da Bahia, Departamento de Comunicação, Salvador, BA, Brasil ORCID: http://orcid.org/0000-0002-1093-5307

\section{Lidiane Santos de Lima Pinheiro}

Universidade do Estado da Bahia, Departamento de Ciências Humanas, Salvador, BA, Brasil ORCID: https://orcid.org/0000-0002-0772-4349

\section{Camila Leite Oliver}

Universidade do Estado da Bahia, Departamento de Linguística, Letras e Artes, Alagoinhas, BA, Brasil ORCID: https://orcid.org/0000-0001-7557-3522

\begin{abstract}
Resumo
Este trabalho pretende contribuir com a epistemologia da comunicação na era da pós-verdade, a partir de um tensionamento semiótico e discursivo a respeito das noções de verdade e efeito de verdade. Para isso, o presente texto discute dilemas relativos aos signos, aos textos, aos discursos e à formação de sentido, que nos parecem não apenas relevantes para compreender aspectos gerais da relação mídia-sociedade, como também aspectos específicos da relação signo-objeto e da relação signo-interpretante, que constituem as bases da problematização sobre construção de realidade, opinião, crença e percepção sobre verdade. Entendemos que o campo de estudos em comunicação, dado seu lugar de destaque no debate sobre as imbricações entre fake news, mídia digital, opinião pública e política, tem um papel fundamental na sociedade contemporânea, que tanto precisa compreender fenômenos semiótico-discursivos.
\end{abstract}

\section{Palavras-chave}

Pós-verdade. Verdade. Efeito de verdade. Semiótica. Análise do discurso. 


\section{Introdução}

Desde 2016, quando o dicionário Oxford elegeu "pós-verdade" (post-truth) como a palavra do ano, muitos estudos em comunicação têm se concentrado nas diversas nuances do ainda recente fenômeno conhecido genericamente por pós-verdade (ALLCOTT; GENTZKOW, 2017; BUCCI, 2018; D'ANCONA, 2018; GENESINI, 2018; MCINTYRE, 2018; SANTAELLA, 2018; TANDOC; LIM; LING, 2018). No presente trabalho, entendemos que, se a semiótica e as teorias do discurso podem contribuir para as dimensões políticas e epistemológicas da comunicação, é porque elas têm algo a dizer sobre os modos de "construção da realidade", os mecanismos operantes na produção de "efeito de verdade", as relações imbricadas entre signo e "referência" e as formas possíveis de "ancoragem" das representações no mundo vivido pelos sentidos e no mundo construído pelos discursos e pelas semioses.

Seria, evidentemente, impossível dar conta de todos os aspectos dessa contribuição semiótica e discursiva em um único artigo. Desse modo, propomo-nos, a seguir, trabalhar no seguinte recorte temático: o problema da falsidade na relação representativa e a possibilidade de averiguação de signos por vias colaterais; o modo semiótico persuasivo (do fazer crer), interpretativo (do crer verdadeiro) e volitivo (do querer ser verdadeiro); a construção dos simulacros e os efeitos de verdade; as relações entre o discurso e poder e as imbricações entre formação de verdade e os contextos históricos. Tais questões serão trabalhadas, primeiramente, do ponto de vista da semiótica de C. Peirce e, posteriormente, sob o prisma de teorias estruturalistas ou pós-estruturalistas, como a semiótica discursiva de Algirdas Greimas e outros estudos vinculados à problemática dos discursos, desenvolvidos pelos franceses Roland Barthes, Michel Foucault e Patrick Charaudeau e, na América Latina, por Eliseo Verón.

Tendo como pano de fundo essas referências teóricas, buscaremos responder, em cada uma das abordagens, a problemas como: o que a teoria em questão (semiótica peirceana, semiótica greimasiana ou estudos dos discursos) teria a contribuir com a comunicação em tempos de pós-verdade? Seria "semioticamente" ou "discursivamente" possível contestar as fake news ou informações falsas? Como a teoria em questão trataria o problema dos "fatos alternativos"? Esses questionamentos guiarão as discussões em cada um dos tópicos a seguir, de modo que, ao passar por eles, seja possível identificar respostas distintas para os mesmos problemas, e que, no entanto, apontem para certo campo de 
contribuição comum dado pelo modo de olhar o fenômeno da pós-verdade pelo prisma dos modelos da significação. Em nosso tempo, parece-nos relevante entender os alcances e as complexidades envolvidas na passagem da discussão sobre a "verdade", que historicamente conferiu legitimidade ao fazer jornalístico, para as que dizem respeito mais aos "efeitos de verdade", de modo que a própria compreensão da ideia de "pós-verdade" tenha algo a ganhar se for possível identificar divergências e convergências teóricas sobre a rede semântica a ela associada.

\section{A importância da via colateral e a contestação semiótica do fake}

Antes mesmo de entrar em questões epistêmicas e políticas, é preciso dizer que a própria noção de verdade é ambígua. Ao longo da história da filosofia, a ideia de verdade já foi entendida como correspondência, revelação, conformidade, coerência e utilidade (ABBAGNANO, 2012; BAZARIAN, 1980). Cada modo de conceituar a verdade enfatiza um aspecto ou outro de um entendimento mais ou menos padrão sobre a verdade estar relacionada ao modo pelo qual algo (da família do "dito") se associa com outro algo (da família do "fato"). Para além dessa controvérsia conceitual, as teorias de bases hermenêuticas, isto é, as que tomam nossa experiência de mundo como fundamentalmente interpretativa (ABBAGNANO, 2012, p. 1187), costumam enfraquecer a própria noção de verdade e enaltecer uma abordagem mais pluralista, falando mais em verdades, no plural, do que em verdade, no singular.

Embora trabalhe com questões muito próximas, Charles Peirce, diferentemente da tradição hermenêutica, explora o universo das interpretações como um processo baseado em cadeias triádicas de signos, processo este que chamou de semiose, e que pode ser tomado como uma busca pelo conhecimento. Para haver semiose, no entanto, é preciso, de acordo com Peirce (2005), não apenas haver um diálogo entre signos e interpretantes destes signos, mas também entre estes dois e os objetos representados, objetos estes capazes de fazer surgir um diálogo entre as concepções mentais e as objeções a ela. E quais seriam essas objeções? Elas viriam das próprias controvérsias do social? Ou seria possível, além de tais controvérsias e construções sociais, imaginar uma objeção ainda mais externa? Qual seria esse objetor externo às construções? Essa é a própria questão que dá origem à noção peirceana de objeto (aquele que é capaz de objetar). E é essa objeção do mundo fenomênico como uma ação vinda de algo exterior à mente que cria para com ela uma 
dualidade, um par que está na origem da noção de secundidade. Em todo ato e toda reação, essa noção está presente. E é com essa base fenomenológica (da dualidade, objeção, conflito, resistência) que o diálogo entre mente e mundo reclama por um domínio mediador, e é daí que a noção de signo (como mediação) se apresenta como base para a semiótica.

No entanto, para Peirce (2005, p. 45-47), só temos acesso ao objeto por meio de signos. Como seria possível, então, falar que o objeto determina o signo, uma vez que ele só é acessado pelo signo? Mais ainda, se todo objeto só é acessado pelo signo, então, como seria possível confrontar o objeto e o signo de modo que tal objeto possa "objetar", exercer-se como secundidade? Aqui, aparece a noção de observação colateral (PEIRCE, 2005, p. 161162). Se todo acesso ao objeto que temos for por um único signo, não será possível testá-lo com objeto, de modo que ele não terá como objetar de fato, não poderá rejeitar qualquer representação que dele for feito. É porque temos outros meios de acessar o mesmo objeto (via outros signos) que podemos, então, falar que um objeto pode resistir. Essa resistência, no entanto, é sentida pela mediação dos signos colaterais, sem os quais não haveria como comparar, confrontar, averiguar e, portanto, rejeitar uma representação. De todo modo, são sempre os signos os responsáveis por fazer as cadeias de estabelecimento de sentidos nas mensagens (tanto as verdadeiras quanto as falsas), e os objetos aparecem por trás dos signos, como uma força que tensiona as interpretações para um lado específico, determinando-as.

É com a noção de mediação que surgem as noções de informação, inferência, aprendizado e também as cadeias de interpretações e semioses, as complexidades dos discursos e os símbolos que permeiam o que chamamos de cultura. Vale frisar que é justamente porque essa teoria da ação do signo de criar novos signos está ancorada no diálogo com objetos dos signos (objetos estes capazes de resistir a tais signos), que Peirce sustenta a esperança de que seja possível a descoberta assintótica e o aprendizado sobre diferentes aspectos do real, por meio das cadeias de semiose. Verdade seria, então, na melhor das hipóteses, o futuro deste processo.

Há, na semiótica peirceana, signos que podem ser considerados evidências de algo, isto é, signos que estão em conexão dinâmica com o objeto, e que, por isso mesmo, chamam a atenção para aquilo a que se referem. Tais signos são chamados de índices (PEIRCE, 2005, p. 66-67). Como já foi sugerido, a função desempenhada por este elemento exterior à relação signo-interpretante é a função de constranger cadeias de semiose a partir de uma 
resistência ou insistência que vem de fora de uma cadeia, e que permite aos interpretantes acessar os vestígios do objeto dinâmico. Nas palavras de Nöth e Amaral, é a presença marcante de índices a realizar uma espécie de "ancoragem extradiscurso" que permite à semiose vislumbrar a presença de fatos no tempo e no espaço. "O critério do ancoramento indexical do objeto do signo no mundo da experiência atual do ouvinte é uma exigência que se aplica a fatos no tempo e no espaço." (NÖTH; AMARAL, 2011, p. 21).

Já no que se refere à verdade racional, Peirce entende que a filosofia e a ciência, quando se propõem a buscar respostas, assumem uma atitude interessada no conhecer. Essa atitude permite tomar a verdade racional como um fim teleologicamente alcançável por um percurso investigativo movido pela esperança na descoberta, sem a qual nenhuma busca seria empreendida. É por meio desse espírito inquiridor que o interpretante importa para o desenvolvimento da semiose, isto é, na associação de signos a criar signos mais complexos. Sua função, desse modo, é jamais aceitar proposições indubitáveis, mas, ao contrário, fomentar o espírito crítico e fazer caminhar a investigação, de modo que crenças surjam no meio do caminho e se transformem pelo diálogo com os níveis indiciais e simbólicos da semiótica, para que, com elas, surjam novos e melhores hábitos de ação.

Se este questionar (suspender os juízos) pode ser traduzido em um abrir-se ao novo, então é a própria base primeira da fenomenologia (a experiência de primeiridade) que pode e deve cultivar a renovação do espírito por meio de doses de frescor. Isto significa que, para além e aquém da verdade factual e racional, existe um universo das possibilidades e qualidades, isto é, dos ícones ou signos por semelhança qualitativa (PEIRCE, 2005, p. 64). Sua função na cadeia de semioses não é propriamente asseverar uma verdade factual ou final, mas a sensibilização para verdades possíveis. Vale lembrar, no entanto, que o universo das possibilidades é, na semiótica de Peirce, o universo da arte, da criatividade, da liberdade, um universo no qual são explorados modos de recombinar, rearranjar elementos, e que não necessariamente diz respeito nem governa fatos do mundo das experiências concretas. Justamente por faltar-lhe ancoragem na existência concreta, os possíveis (primeiridade) não podem se sobrepor aos planos do fato (secundidade) e da lei (terceiridade). Isso não significa, contudo, que a liberdade máxima do universo da primeiridade não desempenhe um papel fundamental na investigação ou na busca pela verdade. 0 seu papel é justamente o de sensibilizar e estimular mentes a produzir novas associações, de modo que tais novas associações possam ser testadas e, em diálogo com a secundidade fatual, com a terceiridade 
cognitiva e também com a constituição de um universo cultural simbólico, façam crescer as representações.

Estamos agora em condições de dizer que posição Peirce assumiria no atual debate epistemológico que interessaria à comunicação na era da pós-verdade. Podemos dizer, diante do exposto, que apesar de não tratar especificamente das relações entre meios de comunicação e sociedade, a teoria peirceana teria muito a contribuir com tal debate, especialmente no que diz respeito aos diferentes papéis dos signos, suas funções representativas e seus desdobramentos em interpretantes na sociedade em vias de midiatização. Dentre os muitos recortes possíveis nesta teoria tão vasta, aqui foram destacados: a diferença fundamental da sua perspectiva epistemológica em relação aos demais estudos hermenêuticos e discursivos; a ênfase na distinção conceitual entre objeto e interpretante, que desempenham papéis diferentes no desdobramento das semioses; o modo pelo qual um objeto pode resistir a interpretações, assumindo sua distintiva secundidade; o papel do índice, isto é, o signo cujo aspecto de secundidade favorece a condição factual da experiência de mundo e sua função sígnica referencial; e o papel da experiência colateral no objetivo de validar ou invalidar representações como falsas.

Neste sentido, a questão sobre a contestação das fake news deveria ser tratada, peirceanamente, como uma questão sobre a validade factual da sua função referencial e indicial, na qual a experiência colateral e a secundidade estejam presentes. Se uma informação veiculada em mídias digitais (ex: uma mensagem de Whatsapp) é falsa, ela o é porque é passível de ser averiguada semioticamente por vias colaterais de representação, por meio de outros indícios, de modo que a confrontação de representações se traduza em um conflito entre os objetos representados, isto é, de modo que a checagem da insistência do objeto possa resultar em um desmentir dos signos que se mostram insustentáveis diante do acesso a novos signos.

Assim, não parece lícito sustentar peirceanamente a existência de "fatos alternativos" ou, ao menos, não é possível sustentar que "fatos alternativos" podem operar continuadamente como índices genuínos. Essa rejeição de versões alternativas sobre fatos deve-se, como vimos há pouco, a uma disputa entre valores indiciais que, no conflito entre representações, possam refutar algumas e manter outras. Isso só é possível por conta da concepção de objeto dinâmico, exterior ao signo e determinante dele. Desse modo, não se pode dizer peirceanamente que criamos objetos, a não ser que utilizemos "objeto" no 
mesmo sentido em que usamos "interpretações" - mas isso seria criar uma ambiguidade nada interessante para a semiótica triádica, pois nela objetos determinam signos e signos determinam interpretantes.

\section{Greimas e o efeito de verdade}

Em uma posição epistemológica distinta da semiótica de C. Peirce, a semiótica greimasiana, herdeira do estruturalismo, não está comprometida com uma busca pela verdade, e não faz qualquer apelo a objetos externos ao plano da linguagem, mas ao contrário, sua posição epistemológica é construtivista, isto é, trata dos objetos construídos por ações sociais. Para Greimas e Courtés (2008, p. 530), a teoria saussuriana, ao postular o caráter autônomo e imanente de qualquer linguagem, impossibilita que se recorra a um referente externo, o que "[...] forçou a semiótica a inscrever entre suas preocupações não o problema da verdade, mas o do dizer-verdadeiro, da veridicção". Desta forma, a Semiótica Greimasiana "enfatiza o fato decisivo de que o objeto que se trata de apreender, o "sentido", não preexiste à sua construção pelos sujeitos" (LANDOWSKI, 2017, p. 148), ou seja, a construção do sentido se dá no interior do discurso como fruto das operações de veridicção e não na sua relação com o referente externo. Assim, para esta teoria, "verdade":

[...] designa o termo complexo que subsume os termos ser e parecer situado no eixo dos contrários no interior do quadrado semiótico das modalidades veridictórias. Não é todo inútil sublinhar que o "verdadeiro" está situado no interior do discurso, pois ele é o fruto das operações de veridicção: isso exclui qualquer relação (ou qualquer homologação) com um referente externo. (GREIMAS; COUTÉS, 2008, p. 529).

A questão da verdade no interior do discurso dá-se então pela inscrição e leitura das marcas de veridicção. A partir destas marcas é que o discurso enunciado se sustenta como verdadeiro ou falso, mentiroso ou secreto. Além disto, o crer verdadeiro não parte do enunciador, a sua afirmação de certeza não basta. 0 crer verdadeiro deve ser instaurado nos dois extremos do canal de comunicação, a partir das ancoragens ou ilusões referenciais que servirão para produzir "sentido de verdade", e esse acordo mais ou menos consciente é o contrato de veridicção ou contrato enuncivo. 
[...] A "verdade", para ser dita e assumida, tem de deslocar-se em direção às instâncias do enunciador e do enunciatário. Não mais se imagina que o enunciador produza discursos verdadeiros, mas discursos que produzem um efeito de sentido "verdade": desse ponto de vista, a produção da verdade corresponde ao exercício de um fazer cognitivo particular, de um fazer parecer verdadeiro que se pode chamar, sem nenhuma nuance pejorativa, de fazer persuasivo. (GREIMAS; COURTÉS, 2008, p.531).

A verdade no interior do discurso não é um a priori, dá-se por procedimentos sintáticos de persuasão (fazer-crer) e a interpretação (crer-verdadeiro). Esse "jogo da verdade" se dá na relação de dois esquemas: parecer/não-parecer (manifestação); ser/nãoser (imanência). Decide-se sobre o "ser do ser", ao estabelecer a imanência a partir da manifestação. É nesse sentido que Landowski (2017, p. 145) aponta sobre a semiótica de Greimas: "[...] dedicar o seu tempo todo e todas as suas forças à procura do 'ser', mesmo sabendo perfeitamente, em outro nível, que tudo é 'parecer'”. Sobre isso, em seu livro, $D a$ Imperfeição , Greimas (2017, p. 25), afirma:

\begin{abstract}
Todo parecer é imperfeito: oculta o ser; é a partir dele que se constroem um querer-ser e um dever-ser, o que já é um desvio de sentido. Somente o parecer, enquanto o que pode ser - a possibilidade -, é, vivível. Dito isso, o parecer constitui, apesar de tudo, nossa condição humana. É ele então manejável, perfectível? E, no final das contas, esta veladura de fumaça pode dissipar-se um pouco e entreabrir-se sobre a vida ou a morte - que importa? (GREIMAS, 2017, p. 25).
\end{abstract}

Se somente o parecer é vivível, o semioticista não deve se esquecer de que a produção de sentido advém de um processo de desdobramento denominado "breagem" enunciativa e abarca duas operações: a "debreagem", vertente disjuntiva do processo, e a “(re)embreagem”, aspecto conjuntivo.

A atividade produtora de significação é de disjunção. Seja verbal, gestual, imagético, ou melodia, o sujeito cria um enunciado que, como objeto autônomo, é disjunto do seu produtor e, portanto, capaz de significar independente do seu produtor. Destarte, tanto para que o dito pareça mais próximo do que se quis dizer, quanto para fazer crer, é que o enunciador ancora o texto, constrói efeitos de verdade, que no processo de (re)embreagem serão atestados ou não pelo seu interlocutor.

Essa parceria entre os interlocutores no ato de criação dos sentidos precisa ser destacada em tempos de pós-verdade e fake news, pois a estratégia de guerra de 
informações baseia-se em produzir informações que pareçam ser plausíveis sobre quem se considera inimigo e difundi-las por meios que as credibilizem (jornais, igrejas, instituições), além de desqualificar outras fontes que possivelmente as contradigam. A ancoragem presente nos argumentos e nos meios de divulgação gera efeitos de verdade e cria simulacros num processo persuasivo de fazer-crer aqueles ou aquelas que depositam confiança nos meios de divulgação ou que compartilham das mesmas referências argumentativas (ideologia). Isto porque, sob o olhar da semiótica greimasiana, não há outra forma de busca do ser senão a partir daquilo que ele manifesta, pois, o simulacro construído pela linguagem é um modo de "existência semiótica" em que a produção do sentido advém dos sujeitos significantes, das suas manifestações discursivas. Ou seja, as modalidades epistêmicas e veridictórias tratam sobre a produção da certeza e da verdade entre os interlocutores, que é a comunicação em definição semiótica. Articuladas a uma certa memória coletiva de usos, a certeza e a verdade dependem de regimes de crença (FONTANILLE, 2015) para determinar o que é e o que não é crível.

Neste sentido, vale também lembrar que para esta teoria semiótica, a verdade é contratual e fiduciária: "[...] toda comunicação humana, toda tratativa, mesmo que não verbal, está fundada sobre um mínimo de confiança mútua e que ela vincula os protagonistas ao que chamamos contrato fiduciário" (GREIMAS, 2014, p. 134). Portanto, esta verdade não é universal e ontológica, mas é construída em cada ato enunciativo e firmada em um sistema de crenças, sendo dependente das estratégias enunciativas desenvolvidas pelos sujeitos da enunciação, na parceria já descrita acima, dos fazeres persuasivos e interpretativos, como coautores (FIORIN, 2016), produzindo e atribuindo sentidos ao enunciado.

[...] De fato, o crer não é somente o fundamento da fé religiosa, mas constitui também e entre outras coisas [...] a instância crucial do discurso científico; numa visão mais ampla, o fazer crer, o qual, enquanto fazer persuasivo, não pode ser tratado independentemente do crer, constitui uma das formas principais da manipulação [...] (GREIMAS; COURTÉS, 2018, p. 107).

Dessa forma, ao descrever o fazer persuasivo do enunciador ("fazer crer") e o juízo epistêmico (crença) do enunciatário, a semiótica discursiva evidencia a relação entre persuasão e crença e a responsabilidade conjunta dos interlocutores no processo de produção de sentidos, pois, é necessária a identificação daquele que interpreta com o que é 
interpretado. É ele quem dirá ser verdadeiro ou não, é ele quem aceita, recusa, admite ou duvida do enunciado.

Portanto, vale reforçar que a semiótica discursiva não se ocupa do que é a verdade, mas, de como o verdadeiro se faz. Ocupa-se de como o enunciador faz parecer ser verdadeiro e como o enunciatário acredita ser verdadeiro. Por conseguinte, o discurso é, para Greimas (2014, p.123),

[...] esse lugar frágil em que se inscrevem e se leem a verdade e a falsidade, a mentira e o segredo; modos de veridicção resultantes da dupla contribuição do enunciador e do enunciatário; suas diferentes posições se estabelecem [...] na forma de um equilíbrio [...] que provêm de um acordo implícito [...] designado pelo nome de contrato de veridicção.

Essa perspectiva torna-se extremamente relevante na análise da eficácia que tem ganhado as fake news na atualidade. Apesar de a crença em tais informações prescindir da existência de um referente externo, ela está ancorada nas relações entre os sujeitos do discurso, o suporte em que as informações circulam, além da forma que os sujeitos percebem o mundo ao seu redor.

Ao tratar desse processo conjunto de produção e apreensão dos efeitos de sentido de verdade, não se pode deixar de destacar que a semiose é condição de existência do sujeito de linguagem que não apenas pensa o mundo, mas que também sente o mundo ao seu redor pela mediação do seu corpo, o qual significa aquilo que o rodeia. É também a partir da mediação do corpo "[...] que as figuras exteroceptivas interiorizam-se e que a figuratividade pode então ser concebida como modo de pensamento do sujeito" (GREIMAS; FONTANILLE, 1993, p. 13).

Assim, tendo a comunicação um forte caráter de fazer persuasivo, em que se buscam utilizar as estratégias enunciativas mais eficazes para alcançar o enunciatário em seu fazer interpretativo, o fazer crer das fake news não precisa se basear apenas em argumentos verbais, mas também, nas ações e relações dos sujeitos, gerando "imaginários passionais", fazendo não com que o sujeito apenas creia ser verdadeiro, mas, com que ele queira ser verdadeiro. A constituição dos imaginários passionais é de fundamental importância para a disseminação das informações de valor moral ou violento, pois, é no simulacro, na vertente semiótica passional, que se manifestam e apreendem-se os sentimentos (medo, ciúme, raiva, alegria, ressentimento). Isto porque, a realidade fenomênica tem papel importante na 
construção do sentido, bem como este é constituído a partir do homem em seu contexto social, cultural, ideológico e emocional.

Desta maneira, ao observarmos a pós-verdade pelo prisma da semiótica greimasiana, cabe antes de tudo uma reflexão prática e política sobre a autoridade que é conferida à noção de verdade como imutável e inquestionável, desconsiderando as relações de poder que perpassam todas as esferas das relações sociais e, portanto, de construção de sentido. Para Greimas (2017), fazer semiótica é, ao contrário, considerar que tanto em relação ao objeto semiótico discursivo, como ao sujeito que olha, não se tem acesso a eles senão mediante o parecer, o qual passa pelas relações sociais e, desta forma, pelas relações de poder. Assim, é preciso observar o objeto de análise como objeto de significação e de comunicação, situado em um dado contexto de produção e de apreensão, analisando as formas que revestem os seus simulacros, até as mais superficiais. Portanto, conhecer as práticas semióticas de produção e interpretação da significação verbal e não verbal, e como essas práticas envolvem os regimes de crença e as modalidades epistêmicas e veridictórias, abre a possibilidade de compreender os processos de formação dos regimes de crença nas mídias digitais e na guerra de informações que se instaurou nestes suportes, de modo que seja possível buscar o aumento da capacidade crítica e uma atitude mais responsável na esfera social.

\section{Dos efeitos de verdade às articulações políticas da verdade}

Mais alinhados com a abordagem estruturalista de Greimas que com a pragmaticista de Peirce, os estudos do discurso se ocupam com os efeitos de sentido que constituem e dos quais são constituídas as relações humanas, sociais e políticas. Eliseo Verón (1981), por exemplo, em Construire l'événement, explora o tema da construção do acontecimento ${ }^{1}$ pelo campo de produção jornalística, investigando o discurso de informação sobre o acidente nuclear de Three Miles Island (1979). Segundo Verón, se os responsáveis pela central nuclear tivessem conseguido esconder o acidente do conhecimento público, seria como se ele nunca tivesse acontecido. Do que conclui: “Os acontecimentos sociais [...] só existem na

\footnotetext{
1 Vale notar a clara diferença entre a ideia de realidade socialmente construída dessa abordagem com a distinção epistemológica peirceana entre o real no sentido mais objetivo (próximo ao objeto dinâmico) e o real no sentido mais subjetivo (que se aproxima mais do polo do interpretante).
} 
medida em que os media dão forma a eles" (VERÓN, 1981, p. 7, tradução nossa). Tal modelo, porém, foi alvo de críticas, por deixar de lado o fato bruto.

Ao detalhar as nuances comunicacionais do debate entre fato e construção, Muniz Sodré reivindica a noção de "[...] fato como conceito para objetos cuja realidade pode ser provada" (SODRÉ, 2009, p. 33), que se diferencia de acontecimento, notícia ou representação social do fato. Para ele, "fato" seria um existente conhecido pelo homem; "coisa" seria um existente empírico, não necessariamente conhecido; "mundo", a totalidade dos fatos (e não das coisas); "caso", aquilo sobre o que se reflete; e "acontecimento", um caso de fato, ou seja, um fato sobre o qual se reflete - jornalisticamente, por exemplo.

Também para o linguista Izidoro Blikstein (2003, p. 17), a realidade extralinguística e sua percepção/cognição não deveriam ser descartadas, como acontece, geralmente, nas teorias da significação. Ele defende a tese de que "[...] a significação do mundo deve irromper antes mesmo da codificação linguística com que o recortamos: os significados já vão sendo desenhados na própria percepção/cognição da realidade".

A realidade extralinguística como uma coisa em si, contudo, não interessa à semiologia saussuriana e tal desinteresse é seguido por Roland Barthes $(1987 ; 1990 ; 2010)$. Nos livros A aventura semiológica e $O$ óbvio e o obtuso, Barthes propõe a análise imanente das mensagens, a partir de sua autonomia estrutural e do abandono de qualquer observação relativa à emissão ou recepção. Em Mitologias, afirma que "O mito não se define pelo objeto da sua mensagem, mas pela maneira como a profere [...]" (BARTHES, 2010, p. 199). Já na introdução do livro, Barthes explica que o mito, forjado pelo abuso ideológico de dissimular uma exposição decorativa do que parece óbvio, é a linguagem que designa "falsas" evidências.

Ao focar na estrutura de mensagens fotográficas e publicitárias, a verdade ou, em suas palavras, a franqueza que lhe interessa é a constituída na duplicidade do sistema de significação.

Não podemos acreditar que a segunda mensagem (de conotação) está 'escondida' sob a primeira (de denotação); [...] mas é mais provável que a primeira mensagem sirva mais sutilmente para naturalizar a segunda: retira-lhe a sua finalidade interesseira [...] Pela sua dupla mensagem, a linguagem conotada da publicidade reintroduz o sonho na humanidade dos compradores: o sonho, quer dizer, sem dúvida, uma certa alienação (a da sociedade concorrencial), mas também uma certa verdade (a da poesia). (BARTHES, 1987, p. 167-168, grifos do autor). 
Barthes, assumindo a verdade dos modos de dizer da retórica poética, dispensa a verdade extralinguística e declara que a duplicidade, por exemplo, da mensagem publicitária, não é incompatível com a franqueza da linguagem, “[...] porque essa franqueza se deve não ao conteúdo das asserções, mas ao caráter declarado dos sistemas semânticos usados na mensagem [...]" (BARTHES, 1987, p. 169, grifos do autor). Logo, desmistificar uma mensagem não é compará-la com a verdade factual, mas, a partir de uma análise da sua construção, desnaturalizar o processo de esvaziamento e deformação de sentidos para sustentar uma estrutura de poder ou um conjunto de valores culturais.

Analisar o sistema de significações, pela maneira como a mensagem é proferida, para desnaturalizar o que Barthes chama de mito, é evidenciar as operações/modalidades enunciativas, conforme propõem os estudos dos discursos. Esses, contudo, buscam extrapolar a imanência dos signos e inquirir, criticar, interrogar a historicidade dos processos constitutivos de sentidos, que têm por efeito, entre outros, instituir verdades.

Sobre o efeito de verdade, Courtine (2006, p. 77) esclarece: “[...] a análise do discurso não pergunta se o discurso diz a verdade, mas tenta perguntar como o discurso assegura como verdade o que foi construído." Foucault, precursor da Análise do Discurso (AD), já alertava que a função do analista não era descobrir uma suposta verdade, reprimida e recalcada, por trás da palavra, de modo que "[...] não se deve imaginar [...] um não-dito ou um impensado que se deveria, enfim, articular ou pensar" (FOUCAULT, 2006, p. 53).

Dominique Charaudeau (2006), ao abordar o discurso midiático, sustenta que analisar os discursos não é separar uma realidade ontológica oculta do desvendamento de suas falsas aparências, nem pensar que por trás do discurso haveria um espaço social mascarado ou deformado por ele:

Não há captura da realidade empírica que não passe pelo filtro de um ponto de vista particular, o qual constrói um objeto particular que é dado como um fragmento do real. Sempre que tentamos dar conta da realidade empírica, estamos às voltas com um real construído, e não com a própria realidade. Defender a ideia de que existe uma realidade ontológica oculta e que, para desvendá-la, é necessário fazer explodir falsas aparências, seria reviver um positivismo de má qualidade. [...] para que o acontecimento exista é necessário nomeá-lo. O acontecimento não significa em si. 0 acontecimento só significa enquanto acontecimento em um discurso. (CHARAUDEAU, 2006, p. 131).

Para a Análise dos Discursos, só se tem acesso ao referente por meio de discursos, que se traduzem em acontecimentos. Logo, o acontecimento - concordando com a leitura de Sodré (2009) - resulta dos processos de produção de sentido e é inseparável do seu relato, pois é a significação que o constrói. Apesar disso, Charaudeau (2006) admite um valor de verdade, baseado em evidência e realizado por instrumentação científica, objetivada e 
objetivante. Diferenciando-se dessa construção de um "ser verdadeiro", o efeito de verdade é produto subjetivo do acreditar ser verdadeiro e baseia-se na conviç̧ão e no saber de opinião/julgamento: "O efeito de verdade não existe, pois, fora de um dispositivo enunciativo de influência psicossocial, no qual cada um dos parceiros da troca verbal tenta fazer com que o outro dê sua adesão a seu universo de pensamento e de verdade." (CHARAUDEAU, 2006, p. 49). Poderíamos concluir que os discursos científico e o jornalístico, por seus modos de dizer, produzem efeito de verdade, mas, mais do que isso, têm também, a princípio, o valor de verdade, frente às evidências que apresentam e à legitimação histórica e social do seu lugar de fala. Já as fake news, apesar de não possuírem valor de verdade, são, muitas vezes, construídas de modo a produzir o efeito de verdade.

Foucault explica que na vontade de verdade das nossas sociedades há um desejo de poder e, por isso, “[...] o discurso não é simplesmente aquilo que traduz as lutas ou os sistemas de dominação, mas aquilo [...] pelo que se luta" (FOUCAULT, 2006, p. 10). A busca pelo controle dos discursos é elucidada por Foucault, quando explica que o acesso a eles é limitado ou impedido por certas regras: “[...] ninguém entrará na ordem do discurso se não satisfizer a certas exigências ou se não for, de início, qualificado para fazê-lo." (FOUCAULT, 2006, p. 37) A promessa de democratização do acesso à internet e, nela, da circulação de enunciados de fontes antes ignoradas parece capaz de resistir à ordem do discurso. A restrição, por exemplo, ao modus operandi do discurso jornalístico tem diminuído, permitindo a indivíduos comuns que dominam a tecnologia e a linguagem cumprir a função de informar, mas a partir de seu próprio código de ética. Inclusive, não há como dissociar a crescente onda de fake news da falta de critérios para se produzir e fazer circular enunciados que acentuam o clima de dúvidas e incertezas na sociedade. A pós-verdade parece, sob esse prisma, ser o efeito da tão recorrente legitimação/deslegitimação de qualificações para o dizer, a tal ponto que a própria ordem do discurso seja, a cada vez, passível de ser questionada por algum tipo de poder.

Investigando a história crítica da verdade em Foucault, Cesar Candiotto (2006) explica que a verdade foi um fio condutor do pensamento do autor. Como a doença mental, o poder ou a sexualidade, para Foucault, a verdade se constitui mediante articulações históricas de modificação e constituição do coletivo de sujeitos que crê e do que se crê verdadeiro, entendendo que não há um significado unívoco naquilo que se denomina verdade: "[...] ela pode ser o mecanismo do qual dispomos para preencher o vazio que 
constitui nosso pensamento finito, ou a justificação racional que elaboramos para compreender nossas práticas cotidianas, ou ainda o escudo protetor que adquirimos diante das vicissitudes que nos ameaçam". (CANDIOTTO, 2006, p. 73) Logo, a análise proposta por Foucault não foca na verdade do enunciado, mas, como vimos em Greimas, no parecer verdadeiro das práticas de enunciação. Assim temos, também em Foucault, a ideia de efeito de verdade - quando os discursos são investidos de um teor verdadeiro, “[...] por mecanismos estratégicos de poder presentes nas práticas sociais [...], com o objetivo de justificar racionalmente aquelas relações de poder" (CANDIOTTO, 2006, p. 69-70).

Por fim, também Eliseo Verón (2004) associa efeito de verdade à ideia de poder, ao discutir o conceito de ideológico. Sempre que a análise de uma superfície discursiva depara com traços das suas condições sociais de produção, tal sistema pode ser nomeado de ideológico. Dito de outro modo, buscar o ideológico é responder como o sentido do discurso remete a determinados mecanismos de base do funcionamento social. Verón diferencia a ideologia do ideológico, entendendo que este não é da ordem superestrutural e, sim, metodológico-epistemológica. É uma dimensão teórica que não se compromete com a contraposição do falso ao verdadeiro nem com a elucidação de algo oculto ou deformado. Tal conceito poderia soar como inútil para a compreensão da pós-verdade, por parecer desnutrir a própria noção de verdade; todavia, se os estudos dos discursos se interessam, não pelo que, mas pelo como e o porquê o discurso diz o que diz, a contribuição de tal perspectiva é justamente a de fazer refletir sobre as estratégias ou os modos enunciativos recorrentes em tal crise epistemológica.

Verón (2004) aproxima o efeito de verdade do 'efeito de naturalização' do mito para Barthes. Diferentemente do mito, porém, no tipo de mensagem fraudulenta que erige o ambiente de pós-verdade, a duplicidade não é evidente e não há franqueza em seu sistema de significação. 0 próprio Verón (2004, p. 57) explica que “[...] embora todo discurso seja submetido a condições determinadas de produção, há alguns que se apresentam como se não o fossem." Com base nisso, seria possível analisar, por exemplo, como as fake news têm obtido sucesso a partir da ocultação (quando não do falseamento) das condições de produção e, muitas vezes, de operações embreantes, não permitindo a identificação dos enunciadores ou da situação de enunciação, de modo que tal ausência as tornam mais verossímeis. 
É fato que muitas fake news são assinadas por fontes conhecidas, como quando o deputado Alberto Fraga (DEM-DF) escreveu no Twitter que Marielle era "ex-esposa do Marcinho VP". Casos como esses, apesar de terem a circulação potencializada pela legitimação da figura pública que enuncia, logo são retificados ou apagados, sendo por isso, talvez, menos nocivos do que aquelas mensagens que, sem traços indiciais da fonte, acabam por circular de forma mais duradoura, conservadas pelo anonimato. Textos que reproduzem a cenografia típica do discurso científico ou jornalístico, com seus modos de dizer objetivos, e fotografias, cujo estatuto semiótico é ainda o de fragmento testemunhal da realidade, mesmo com a ancoragem de legendas duvidosas, são compartilhados pelos usuários da rede pelo simples acreditar ou querer ser verdadeiro, como já explicado via Greimas.

As fake news - ou as circunstâncias geradoras do atual contexto de crise epistemológica - preocupam porque resultam em fixação de crenças e mudanças de atitude. Diante disso, urge refletir sobre os processos de enunciação e instauração da pós-verdade na sociedade midiatizada, buscando neles traços ideológicos ou indícios dos mecanismos de base do funcionamento social, e compreender os efeitos de sentido de verdade como efeitos de crença e de poder - proposta com a qual os estudos dos discursos têm muito a contribuir.

\section{Considerações finais}

Neste trabalho, perpassamos alguns pontos que conceitualmente nos pareceram importantes de serem discutidos dentro do guarda-chuva da pós-verdade. Discutimos, a partir da semiótica peirceana, as noções de objeto, secundidade, índice e observação colateral, como subsídios para uma discussão a respeito dos referentes dos signos. Em seguida, discutimos a noção de efeito de verdade a partir da perspectiva greimasiana, de natureza imanentista, construtivista e estruturalista, de modo a esclarecer as relações entre persuasão, interpretação e volição, entendidos como importantes fatores no fenômeno da pós-verdade. Por fim, foram chamadas para o debate as teorias pós-estruturalistas do discurso, destacando o papel das "construções de realidades" como disputas políticas.

Ao longo deste percurso, tentamos situar a polissemia do tecido conceitual no qual as noções de verdade e efeito de verdade se constituem, tomadas aqui abertamente como uma questão que pode ser trabalhada do ponto de vista dos estudos semióticos e discursivos. Sob este prisma, o presente trabalho ajudou a esclarecer o que está em jogo no 
campo das possíveis construções de fake news e "fatos alternativos" com os quais cada vez mais temos que aprender a lidar nas dinâmicas sociais contemporâneas.

Em linguagem comum, falamos com frequência que $\mathrm{X}$ é falso, que fulano está mentindo. Em tempos de pós-verdade, em que discursos falsos, distorcidos, sem base empírica ou racional exercem efeitos notáveis na cultura e na vida social, esse tipo de questão parece ainda mais relevante, dado que o cinismo, a falsidade deliberada e a mentira deslavada agridem, atacam, matam, de modo que questões sobre signo, crença e política se imbricam de forma cada vez mais inextricável. Para Hannah Arendt (2016), "política" e "verdade" são esferas distintas, só que, muitas vezes, se confundem, porque as opiniões, indispensáveis ao poder, passam-se por verdadeiras e causam efeitos epistêmica e politicamente danosos.

Como vimos, as correntes europeias mais influentes do século XX no que se refere aos estudos semiológicos e discursivos parecem concordar que o problema da verdade é um falso problema. Para essas correntes, antes de qualquer consideração sobre o que vem a ser o verdadeiro, é preciso entender os contextos sociais e/ou as trajetórias de formação de determinada forma de pensar presente em uma cultura ou coletividade, a influenciar os pensamentos dos indivíduos que a ela pertencem. Dentro deste paradigma, a noção de verdade não pode ser tomada em si, sob pena de violar o princípio da construção social da realidade. Mais ainda, a própria pretensão de falar sobre verdade é, por si só, uma atitude discursivamente suspeita, na medida em que o plano de enunciação é aquele em que estão contidas as disputas, as intenções, os interesses e as controvérsias do social, de modo que um discurso que se pretende verdadeiro deve ser interpretado como um discurso que pretende se fazer dominante.

Diferente dessa tradição que vincula saber e poder, Peirce elabora uma semiótica que não opera com a ideia de construção dos objetos (chamados por ele de "objetos dinâmicos") pela cultura e sociedade, mas pela construção de interpretantes, a partir de objetos, e sempre mediados por signos. Isso significa que, em dissonância com as vertentes construtivistas, em Peirce, há uma tentativa de resgatar um princípio de objetivação da experiência de mundo, preservando tal função semiótica de referência como distinta da função de produção de sentido, mais própria da interpretação. Tal postura epistemológica é baseada numa articulação muito peculiar entre um certo logicismo e um realismo, que o próprio Peirce, ao unificá-los, batizou de pragmatismo. Este não era um projeto de 
dominação, mas um projeto de radicalização do método de investigação interessado no crescimento da cognição, na busca intersubjetiva de conhecer objetos dinâmicos e na formação de hábitos de ação mais coerentes com a realidade coletivamente experimentada. Vale destacar, aliás, que a proposta semiótica de Peirce não pode, em nenhum sentido, ser confundida com um dogmatismo ou mesmo com um realismo platônico. 0 próprio Peirce nunca pretendeu ser "o legítimo representante da verdade", e, por isso mesmo, sua teoria faz apelo à noção de comunidade e ao papel que o futuro das investigações desempenha na sua epistemologia antinominalista.

Uma vez que chegássemos a uma espécie de busca pragmática pela verdade, de acordo com Peirce, estaríamos engajados em uma espécie de projeto "anti-pós-verdade", de modo que a ciência, em geral, e a comunicação, em particular, tivessem o objetivo de fazer caminhar a semiose de um modo bastante compromissado com os efeitos possíveis de suas representações. Por outro lado, uma vez considerado o amálgama da "epistemologia política" com o qual as teorias semióticas e discursivas europeias se comprometem desde sempre, a própria ideia de pós-verdade estaria imersa em um campo de batalha do social, de modo que os efeitos de verdade, os mitos e a ordem dos discursos não podem ser combatidos senão por meio de novas produções de efeitos de verdade, novas conotações, mitos e ordens de discursos.

Como vimos no presente trabalho, do ponto de vista da relação mídia-sociedade no âmbito da pós-verdade, diversas contribuições advindas de teorias dos signos e discursos podem ser bem-vindas. Se bem entendidas, todas elas teriam bastante a acrescentar aos estudos da comunicação. Diversos estudos aplicados trazem e poderiam continuar a trazer para a discussão sobre efeitos de verdade casos concretos que ilustrassem o modo como os conceitos aqui discutidos serviriam para o entendimento, por exemplo, sobre os atores que se articularam nas trincheiras das fake news nas eleições de 2018 no Brasil. Aqui, no entanto, não se tratava de aplicar em casos concretos os conceitos trabalhados (como experiência colateral, indexicalidade, de efeito de verdade, mito, ordem do discurso etc.), mas antes mapear e discutir suas diferentes origens epistemológicas e as redes semânticas às quais estão vinculados, ajudando o campo da comunicação a se munir cada vez mais de um poderoso arsenal conceitual para que se possa entender e, quem sabe, conter os danos epistêmicos e políticos que a união entre as "mídias" e as "mentiras deliberadas" possa trazer para nossa sociedade. 


\section{Referências}

ABBAGNANO, Nicola. Dicionário de filosofia. São Paulo: WMF Martins Fontes, 2012.

ALLCOTT, Hunt; GENTZKOW, Matthew. Social media and fake news in the 2016 election. Journal of Economic Perspectives, [s. l.], v. 31, n. 2, p. 211-236, 2017.

ARENDT, Hannah. Entre o Passado e o Futuro. São Paulo: Perspectiva, 2016.

BARTHES, Roland. A aventura semiológica. Lisboa: Edições 70, 1987.

BARTHES, Roland. Mitologias. Rio de Janeiro: DIFEL, 2010.

BARTHES, Roland. 0 óbvio e o obtuso: ensaios sobre fotografia, cinema, teatro e música. Rio de Janeiro: Nova Fronteira, 1990.

BAZARIAN, Jacob. 0 problema da verdade. São Paulo: Ed. Símbolo, 1980.

BLIKSTEIN, Izidoro. Kaspar Hauser ou A Fabricação da Realidade. São Paulo: Cultrix, 2003.

BUCCI, Eugênio. Pós-política e corrosão da verdade. Revista USP, [s. l.], n. 116, p. 19-30, 2018.

CANDIOTTO, C. Foucault: uma história crítica da verdade. Trans/Form/Ação, v.29, São Paulo, 2006, p.65-78.

CHARAUDEAU. Patrick. Discurso das mídias. Tradução Ângela S. M. Corrêa. São Paulo: Contexto, 2006.

COURTINE, Jean-Jacques. Metamorfoses do discurso político: as derivas da fala pública. Tradução Nilton Milanez, Carlos Piovezani Filho. São Carlos: Claraluz, 2006.

D’ANCONA, Matthew. Pós-verdade. Barueri: Faro Editorial, 2018.

GENESINI, Silvio. A pós-verdade é uma notícia falsa. Revista USP, [s. l.], n. 116, p. 45-58, 2018.

FIORIN, José Luiz. As astúcias da enunciação. 3. ed. São Paulo: Contexto, 2016.

FONTANILLE, Jacques. Formes de vie. Liège: Presses Universitaires de Liège, 2015.

FOUCAULT, Michel. A ordem do discurso. Tradução Laura Fraga de A. Sampaio. 13. ed. São Paulo: Loyola, 2006.

GREIMAS, Algirdas Julien. Sobre o sentido II: Ensaios semióticos. São Paulo: Nankin: Edusp, 2014. 
GREIMAS, Algirdas Julien. Da Imperfeição. Tradução Ana Cláudia de Oliveira. 2.ed. São Paulo: Estação das Letras e Cores, 2017.

GREIMAS, Algirdas Julien \& COURTÉS, Joseph. Dicionário de Semiótica. Tradução: Alceu Dias Lima e Diana Luz Pessoa de Barros. São Paulo: Contexto, 2008.

GREIMAS, Algirdas Julien \& FONTANILLE, Jacques. Semiótica das Paixões. São Paulo: Ática, 1993.

LANDOWSKI, Eric. Com Greimas: Interações semióticas. Tradução: Ana Cláudia de Oliveira. São Paulo: Estação das Letras e Cores, 2017.

MCINTYRE, Lee. Post-truth. Cambridge, Massachusetts; London, England: The MIT Press, 2018.

PEIRCE, Charles Sanders. The essential Peirce: selected philosophical writings. v. 1 e v. ed. Bloomington and Indianapolis: Indiana University Press, 1998.

PEIRCE, Charles Sanders. Semiótica. São Paulo: Perspectiva, , 2005

SANTAELLA, Lucia. Epistemologia Semiótica. Cognitio, [s. l.], v. 9, n. 1, p. 93-110, 2008.

SANTAELLA, Lucia. A Pós-Verdade é Verdadeira ou Falsa? Barueri: Estação das letras e cores, 2018.

SODRÉ. Muniz. A narração do fato: notas para uma teoria do acontecimento. Petrópolis, RJ: Vozes, 2009.

TANDOC, Edson C.; LIM, Zheng Wei; LING, Richard. Defining "Fake News": A typology of scholarly definitions. Digital Journalism, [s. l.], v. 6, n. 2, p. 137-153, 2018. Disponível em: http://doi.org/10.1080/21670811.2017.1360143

VERÓN, Eliseo. Construire l'événement: les médias et l'accident de three mile island. Paris: Les editions de minuit, 1981.

VERÓN, Eliseo. Fragmentos de um tecido. São Leopoldo: UNISINOS, 2004.

\section{From truth to truth effects: contributions of semiotic and discourse theories to the epistemology of communication in times of post-truth}

\footnotetext{
Abstract

This work aims to contribute to the epistemology of communication in the post-truth era, based on a semiotic and discursive tension regarding the notions of truth and truth
} 
effect. For this, the present text discusses dilemmas related to signs, texts, discourses and the formation of meaning, which seem to us not only relevant to understand general aspects of the media-society relationship, but also specific aspects of the sign-object and the sign-interpretant relationship, which constitute the bases of the problematization about the construction of reality, opinion, belief and perception about the truth. We understand that the field of studies in communication, given its prominent place in the debate about the imbrications between fake news, digital media, public and political opinion, has a fundamental role in contemporary society, which so much needs to understand semiotic-discursive phenomena.

\section{Keywords}

Post-truth. Truth. Truth effect. Semiotics. Discourse analysis.

\section{Autoria para correspondência}

Tarcísio de Sá Cardoso

tscardoso@gmail.com

\section{Como citar}

CARDOSO, Tarcísio de Sá; PINHEIRO, Lidiane Santos de; OLIVER, Camila Leite. Da verdade aos efeitos de verdade: contribuições das teorias semióticas e do discurso à comunicação em tempos de pós-verdade. Intexto, Porto Alegre, n. 52, e-103489, jan./dez. 2021. DOI: http://dx.doi.org/10.19132/18078583202152.103489

Recebido em 27/05/2020

Aceito em 07/11/2020

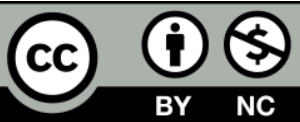

